\title{
ENSINO DE LÍNGUAS: PROBLEMAS E ALTERNATIVAS CONTEMPORÂNEOS: UMA APRESENTAÇÃO
}

\author{
Edmilson Luiz Rafael
}

Rita de Cássia Souto Maior Siqueira Lima

Para apresentarmos esse número, retomamos aqui as palavras de Morin $(2009)^{1}$, ao afirmar que a primeira finalidade do ensino foi citada por Montaigne quando este disse: "mais vale uma cabeça bem-feita que bem cheia". Aquele autor esclarece que o saber meramente acumulado não dispõe, e concordamos com ele, de seleção e organização que lhe dê sentido. Foi com esse princípio de sentido e considerando a finalidade primeira do ensino citada acima que temos o prazer de apresentar aos leitores da Revista Leia Escola o Dossiê sobre Ensino de Línguas: problemas e alternativas contemporâneos.

A obra foi organizada a partir da seleção de artigos escritos por pesquisadores/as de diferentes lugares do Brasil que tratam de diversos enfoques sobre o ensino de línguas - que vão desde aspectos relacionados à formação de professores até discussões sobre métodos e estratégias de ensino. Essa diversidade de olhares nos permitiu além de ligar saberes - e não apenas acumulá-los - reelaborá-los em um conjunto harmônico que nos revelou aspectos do ensino/aprendizagem de línguas na contemporaneidade que refletem e refratam (no sentido bakhtiniano do termo) a complexidade do espaço multidimensional que é a sala de aula. No conjunto dos textos, ou a depender do caminho que queira trilhar no dossiê, caro leitor, você poderá reconhecer o que parece ser mais contemporâneo nas discussões sobre o ensino/aprendizagem.

No artigo A construção identitária de professores de inglês em cursos livres, Adail Sobral e Maria Waleska Peil empregam os princípios da análise dialógica de Mikhail Bakhtin, tal como apresentada por Brait (2006) e Sobral (2009), para analisar a identidade de professores (HALL, 2012; DUBAR, 2009), investigando de que forma

\footnotetext{
${ }^{1}$ MORIN, Edgar. A cabeça bem-feita: repensar a reforma reformar o pensamento. Ed.16. Tradução: Eloá Jacobina. Rio de Janeiro: Bertrand Brasil, 2009.
} 
esses professores de língua inglesa se autoidentificam e avaliam seu perfil profissional na contemporaneidade (HALL, 2012; BAUMAN, 2009). Partindo da consideração de que esses indivíduos encontram-se fragmentados, os autores observam a diversidade encontrada em cursos livres de língua inglesa, o que faz com que esses, ainda segundo os autores, tenham um caráter único. Por outro lado, continuam a reflexão, o crescimento desses ambientes parece caminhar lado a lado com o processo de declínio do ensino do inglês nas escolas, sejam estas da rede pública ou particular de ensino. Com essas observações, discutem sobre o que é a formação de professores de língua estrangeira a partir de Celani (2006), Moita Lopes (2006), dentre outros. Os pesquisadores concluem que, segundo os sujeitos pesquisados, ser professor extrapola os limites da academia, pois deve vir do indivíduo e de sua busca pela diferença.

Com o artigo $O$ texto no contexto: uma proposta escritural, Girlene Portela, a partir de autores como Koch (1997) e Leffa (1996), busca contribuir para a discussão acerca do que vem a ser um texto eficiente, a fim de empreender proposta de ampliação das possibilidades de trabalho com textos em sala de aula, visando a mudanças no hábito do professor que objetiva interferir na vida de seus alunos. Citando autores como Dijk (1978), Greimas e Courtés (1989), Hayes e Flower (1980), a autora conduz sua discussão considerando a escrita como uma atividade que exige múltiplas capacidades e o texto como local onde o diálogo estabelecido pressupõe os interactantes. Sendo assim, o processo argumentativo, segundo ela, além de ser fruto de um acordo prévio entre o falante/escritor e o seu interlocutor/leitor, exprime-se nas premissas da argumentação (PERELMAN, 1977). A autora acredita que nossos estudantes não escrevem por vários motivos, dentre os quais a falta de hábito, a falta de motivação e, principalmente, por falta de um feedback. Com essa discussão, a pesquisadora busca auxiliar os professores a melhor conhecerem as teorias que embasam os manuais escolares, apresentando, também, propostas de ensino-aprendizagem para a leitura e escrita em sala de aula.

No artigo intitulado Conhecimentos linguístico-discursivos na sala de aula de língua portuguesa: desenvolvendo 'táticas' para desobedecer a propostas prontas, Rita Zozzoli propõe uma reflexão sobre o trabalho prático efetuado com os conhecimentos linguístico-discursivos na sala de aula de língua portuguesa, através de análise de exercício de livro didático. Para a autora, torna-se fundamental não ignorar que o discurso da escola é que poderá ou não reforçar o peso social de uma variedade de prestígio em detrimento de outra já estigmatizada. Segundo ela, vale alertar para o fato 
de que existem várias maneiras de falar, algumas mais consideradas do que outras e que, dependendo da situação de comunicação, do gênero discursivo utilizado, é mais oportuno utilizar aquelas mais aceitas por quem tem poder na situação. Zozzoli considera útil perseguir o objetivo de constituição de uma gramática do aluno (ZOZZOLI, 1999) e que, ao invés de o professor fornecer explicações prontas em sala e aula, buscar propiciar ao aluno oportunidades de reflexão, a partir das próprias dificuldades surgidas. No entanto, os professores de um modo geral, ainda segundo a autora, não possuem autonomia relativa (ZOZZOLI, 2006) e não apenas pelas carências de formação, mas também pelo fato de que devem seguir programas e livros didáticos ao pé da letra. Ela defende, juntamente com De Certeau (1996) e Santos (2007, 2008), uma formação necessária ao professor de LM para que esteja em condições de “desobedecer" ao que já está posto. Exemplifica com um exercício de livro didático e conclui que as propostas de ensino continuam sugerindo a aplicação de conteúdos, combinando-a a práticas reconhecidamente tradicionais. Considera também que, nesse contexto, o professor está frequentemente confinado dentro do que preestabelece o discurso dos produtores (DE CERTEAU, 1996).

Mônica Cavalcante, no artigo intitulado Função discursiva dos elos coesivos referenciais, propõe apresentar dois conteúdos amplamente abordados na Linguística de Texto, mas geralmente, segundo a autora, separados nas pesquisas sobre o assunto: elos coesivos e elementos referenciais. Considera que os fatores de natureza linguística e conceitual estariam para a textura interna do texto, alguns fatores de ordem pragmática estariam para a textura externa e ainda há outros que estão nos dois campos. A autora propõe uma noção mais ampla de coerência e outro olhar para a coesão que não se circunscreva a aspectos formais da articulação de enunciados. Sendo assim, a autora propõe uma revisão dos recursos coesivos, distribuídos segundo a ótica da referenciação, e considera ser importante que essa dupla perspectiva, segundo a estudiosa, pautada na construção da coerência revele os vários dispositivos de que dispõe a língua para remodelar os sentidos.

No texto Ler, Escrever, "Pontuar": a construção da autoria, Maria Marta Furlanetto assume que o processo de autoria se dá pela tríade que apresenta no título, entendendo que pontuar seria deixar traços de organização textual e de escolhas singulares ao mesmo tempo. A autora associa ainda os efeitos de produção autoral àquilo que diz se denominar estilo, sem o que não seria possível, ainda segundo a pesquisadora, reconhecer a autoria. Ela promove a discussão baseada em algumas 
noções da Análise de Discurso - como função-autor, função-leitor e efeito-leitor associadas a outras de um campo mais amplo, e diz ter o objetivo de refletir sobre esses processos, mostrando que julga ser necessário conhecê-los e considerá-los em ambiente escolar para que a produção de um efeito de autoria se consubstancie. Discute, para isso, o domínio entre o saber-ler e saber-decifrar, a partir de Foucambert (1994), e a diferença entre leitor semântico e leitor crítico, com Eco (1995), entendendo que texto supõe aquilo que Orlandi (2001, p. 16) chama de "textualização da memória". Discutindo sobre a Proposta Curricular de Santa Catarina, a autora entende que assim como no processo de letramento existem níveis num continuum (TFOUNI, 2001), a autoria se processa em níveis ou etapas. Do ponto de vista pedagógico, reflete sobre autoria a partir da concepção de gêneros do discurso e a concepção de projeto discursivo, além de se inspirar em trabalhos de Possenti (2009a; 2009b). Por fim, a autora entende que os indícios de autoria devem ser paulatinamente reforçados e estimulados com meios adequados as experiências bem-sucedidas conduzem à necessidade de pensar, particularmente no Ensino Fundamental, em criar e manter uma tensão saudável entre ordenação e dispersão em trabalho aberto de jogo de vozes - do caos à criação singular ou coletiva.

As autoras Darcília Simões e Rosane Reis, no artigo intitulado Prática de ensino da redação: uma proposta icônico-digital, apresentam proposta de ensino de redação, pautada nas competências e habilidades inscritas em documentos oficiais. Por considerarem que os ambientes virtuais de aprendizagem permitem a convivência, a interligação dos saberes e a troca de experiências, as autoras acreditam que esses podem ser um caminho para a formação de redatores proficientes e demonstram o modo como vêm trabalhando o ensino de redação em turmas preparatórias para concursos vestibulares, a partir de um construto teórico capaz de subsidiar uma prática didática eficiente em aulas virtuais, como a Teoria da Iconicidade Verbal (SIMÕES, 2009). As autoras revisitam e discutem as noções de competências e as habilidades linguísticas e reveem o modo como as redações dos alunos são corrigidas e encaminhadas para a reescritura como forma eficiente para a aprendizagem da língua padrão. Por fim, elas consideram que ensinar os fatos da língua apoiados nos valores icônicos e indiciais das formas da língua consolidam uma aprendizagem pela assimilação das estratégias de estruturação verbal, tornando os alunos mais conscientes do uso da língua e preparados para iniciar o trabalho de leitura e produção mais consciente. 
Os autores Washington Farias e Aloísio Dantas, no artigo Língua, gramática e ensino: mudar as gramáticas ou mudar de gramática?, consideram que há uma nova forma e uma nova fase de instrumentação da língua no Brasil já que as obras dos linguistas-gramáticos se constituem como novos lugares simbólico-políticos de constituição e legitimação de sentidos sobre a língua no Brasil. Partindo dessa afirmativa e de suas implicações, analisam a movimentação do discurso gramatical brasileiro contemporâneo, com o intuito de observar como se materializa em três gramáticas recentes: a Moderna gramática da língua portuguesa (BECHARA, 1999), a Gramático Houaiss da língua portuguesa (AZEREDO, 2008) e a Gramática do português brasileiro (PERINI, 2010). Segundo os autores, a análise das gramáticas possibilita flagrar deslocamentos de sentidos do discurso gramatical, os quais, segundo ainda eles, assinalam uma disputa política pelo poder de (re)dizer/(re)definir a língua do brasileiro. Para o estudo, consideram a heterogeneidade e os efeitos de unidade da Formação Discursiva (PÊCHEUX, 1997), a questão do sujeito do discurso e a relação sujeito/Sujeito que constitui não um sujeito idealista ou transcendente, mas uma categoria teórica explicativa do fato de que o indivíduo se torna sujeito pelo reconhecimento numa forma-sujeito histórica. Os autores concluem que as três gramáticas analisadas se apresentam como atualização do discurso gramatical brasileiro, entretanto, não apresentam o mesmo efeito de sentido. De fato, eles demonstram que há uma heterogeneidade de posições que ressignificam de modo distinto o discurso gramatical, com implicações sobre os sentidos do que é ser gramático, da forma da gramática e de seu papel no ensino da língua.

Esperamos que as reflexões acerca dos problemas e alternativas sobre ensino de línguas apresentadas pelos autores dos artigos reunidos neste Dossiê constituam ponto de partida e inspirem produtivas investigações sobre os objetos aqui focados ou outros que surjam no caminho da leitura. 